\section{In Vitro Antimalarial Activities of the Microbial Metabolites}

Sir:

In the course of our screening program to discover antimalarial antibiotics from soil microorganisms and antibiotic library of the Kitasato Institute for Life Sciences which are active against drug resistant parasites in vitro and in vivo, we previously reported that the polyether antibiotics X-206 and K-41 exhibited selective and potent antimalarial activities in vitro and in vivo ${ }^{1,2}$. Now, we found that the metabolites from a fungal strain FKI-0266 and an actinomycete strain K99-5147 have the potent activities in vitro. They were identified as a known linear peptide antibiotic, leucinostatin $\mathrm{A}^{3)}$ and a known tetracyclic quinone glycoside antibiotic, polyketomycin ${ }^{4)}$, respectively (Fig. 1). Furthermore, we found that takaokamycin ${ }^{5}$, a compound in the antibiotic library of our institute, has potent activity in vitro. Since the structure of takaokamycin has not been determined, we studied it by physico-chemical methods. A cyclic peptide antibiotic hormaomycin ${ }^{6)}$ (Fig. 1) was previously reported to have almost the same physico-chemical properties as takaokamycin except some difference in ${ }^{1} \mathrm{H}-\mathrm{NMR}^{7}$. We concluded that takaokamycin was identical with hormaomycin by re-examination of ${ }^{~} \mathrm{H}$ and ${ }^{13} \mathrm{C}$-NMR spectra of takaokamycin. We report here in vitro antimalarial activities of leucinostatin $\mathrm{A}$, polyketomycin and takaokamycin (hormaomycin) in comparison with those of clinically used antimalarial drugs.

Leucinostatin A, polyketomycin and takaokamycin were

Fig. 1. Structures of leucinostatin A, polyketomycin and takaokamycin.

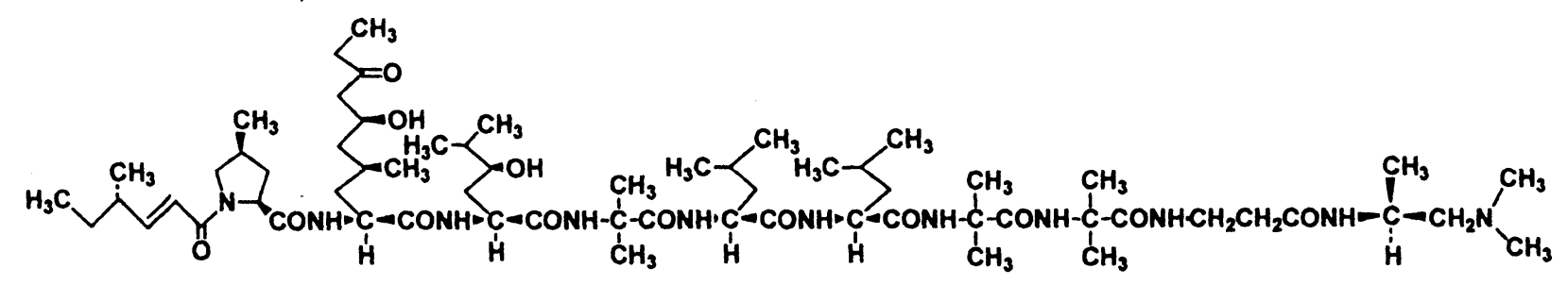

FKI-0266 (leucinostatin A)<smiles>COC1=CC(=O)c2c(O)c3c(c(C)c2C1=O)C[C@]1(O)C(=O)C(=O)[C@](O)(C(=O)C(=C(C)O)C(=O)[C@H]1C)[C@H]3O</smiles>

K99-5147 (Polyketomycin)

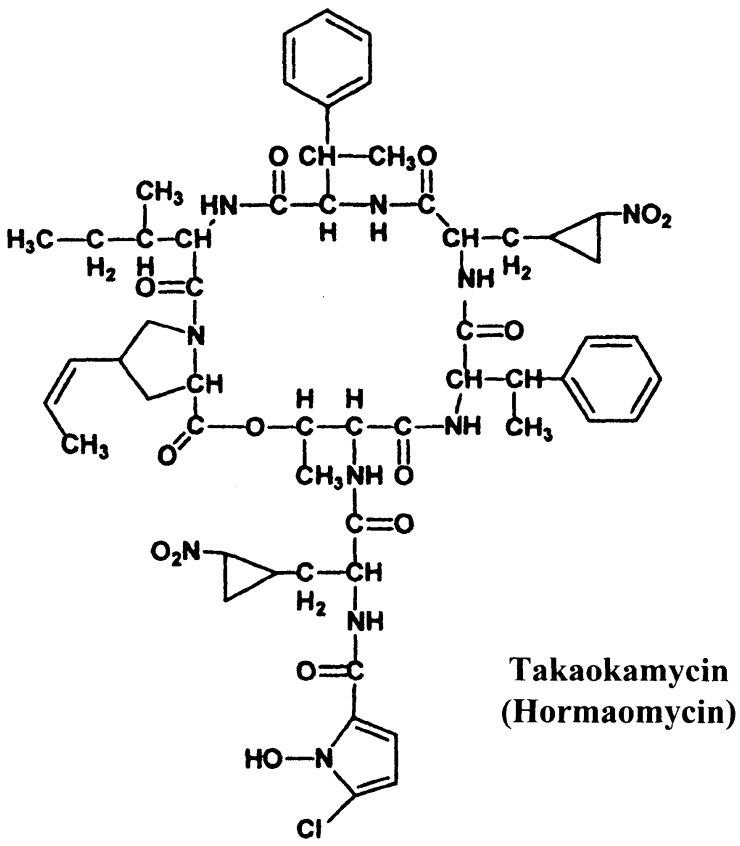


purified from the culture broth of a fungal strain FKI-0266, an actinomycete strain K99-5147 and a Streptomyces sp. AC-19785), respectively. In vitro activities against Plasmodium falciparum strains $\mathrm{K} 1$ (drug resistant) and FCR3 (drug sensitive), and cytotoxicity against human diploid embryonic cell line MRC-5 were measured as described previously ${ }^{1)}$.

The in vitro antimalarial activities of leucinostatin A, polyketomycin, takaokamycin and the standard drugs are shown in Table 1. Leucinostatin A showed more potent activity against the drug resistant $\mathrm{K} 1$ and the drug sensitive FCR3 strains of $P$. falciparum than the clinically used antimalarial drugs, artemether, artesunate, artemisinin, chloroquine and pyrimethamine. Polyketomycin and takaokamycin showed similar activities against the $\mathrm{K} 1$ strain of $P$. falciparum as chloroquine. Respective $\mathrm{IC}_{50}$ values of the three microbial metabolites against the $\mathrm{K} 1$ strain was similar to those against the FCR3 strain, indicating that they were also active against the drug resistant strain. We then investigated the cytotoxicity of the three microbial metabolites against MRC-5 cells. The $\mathrm{IC}_{50}$ values of leucinostatin $\mathrm{A}$, polyketomycin and takaokamycin were 133, 14,735 and 53,879 nM, respectively. Leucinostatin $\mathrm{A}$ and takaokamycin showed moderate selectivity indexes with the ratios in the ranges of 92 148 and 45 333 for the MRC-5 cells/K1 strain and MRC-5 cells/FCR3 strain, respectively. On the other hand, polyketomycin showed lower selectivity indexes with the ratios of 16 and 12 for the MRC-5 cells/K1 strain and MRC-5 cells/FCR3 strain, respectively. These are the first data to show antimalarial activities of leucinostatin A, polyketomycin and takaokamycin.

Antimicrobial activities of a linear peptide gramicidin D, and cyclic peptide valinomycin and gramicidin $\mathrm{S}$ were reported by A. MCCOLM \& N. MCHARDY ${ }^{8)}$ and C. Gumila et al. ${ }^{9)}$. These antibiotics act as ionophores at plasma membrane. Leucinostatin A was reported to act as an inhibitor of the mitochondrial ATP synthesis $^{10)}$ and photophosphorylation ${ }^{11)}$. P. CSERMELY et al., reported that leucinostatin A acts also as a weak ionophore facilitating the transport of mono- and divalent cations through the plasma membrane ${ }^{12)}$. These reported data cited above may suggest that both leucinostatin $\mathrm{A}$ and takaokamycin (hormaomycin) act as ionophores against Plasmodia, though no report is available on the mode of action of takaokamycin.

Polyketomycin is structurally similar to dutomycin ${ }^{13)}$, an anthracycline antibiotic. The mode of action of
Table 1. Antimalarial activities of microbial metabolites and the antimalarial drugs against $\mathrm{K} 1$ and FCR3 strains of Plasmodium falciparum.

\begin{tabular}{lcc}
\hline & \multicolumn{2}{c}{ IC50 (nM) } \\
\cline { 2 - 3 } Compound & K1 strain & FCR3 strain \\
\hline Leucinostatin A & 0.9 & 0.4 \\
Polyketomycin & 521 & 694 \\
Takaokamycin & 587 & 1,207 \\
Artemether & 7.6 & 2.2 \\
Artesunate & 11 & 2.7 \\
Artemisinin & 24 & 18 \\
Chloroquine & 357 & 29 \\
Pyrimethamine & $>100,000$ & 7.8 \\
\hline
\end{tabular}

anthracycline antibiotics is well-known as the inhibitors of nucleic acid synthesis. Recently, K. NAGAO et al., ${ }^{14)}$ reported that DMI-2, a derivative of dutomycin, showed strong inhibition of $N^{6}$-methyladenine-DNA methyltransferase. Polyketomycin may act as the inhibitor of nucleic acid synthesis in Plasmodia.

Further studies on in vivo test and other biological activities of leucinostatin A, polyketomycin and takaokamycin are in progress.

\section{Acknowledgments}

This work was supported, in part, by funds from the UNDP/World Bank/WHO Special Program for Research and Training in Tropical Diseases (grants ID 990806 and ID A10124), and Grants-in-Aid for Scientific Research (A) from the Ministry of Education, Culture, Sports, Science and Technology, Japan. A part of work was supported by The 21 st Century COE Program, Ministry of Education, Culture, Sports, Science and Technology (MEXT). We are grateful to Dr. K. HATA, JPMW Coordination Center, for valuable discussion. We also thank Miss. A. Kohana and C. Manabe the Kitasato Institute, for the antimalarial assay, Mr. Y. YAmAGUCHI and Miss A. Matumoto Kitasato Institute for Life Science, for technical assistance.

\footnotetext{
* Corresponding author: omura-s@kitasato.or.jp
} 
Research Center for Tropical Diseases, The Kitasato Institute,

${ }^{\dagger}$ School of Pharmaceutical Science, Kitasato University,

${ }^{+\dagger}$ Kitasato Institute for Life Science, Kitasato University,

5-9-1 Shirokane, Minato-ku, Tokyo 108-8642, Japan

(Received December 9, 2002)

\section{References}

1) Otoguro, K.; A. Kohana, C. Manabe, A. Ishiyama, H. Ui, K. Siomi, H. Yamada \& S. Ōmura: Potent antimalarial activities of polyether antibiotic, X-206. J. Antibiotics 54: 658 663, 2001

2) Otoguro, K.; A. Ishiyama, H. Ui, M. Kobayashi, C. Manabe, G. Yan, Y. Takahashi, H. Tanaka, H. YAMADA \& S. OMURA: In vitro and in vivo antimalarial activities of the monoglycoside polyether antibiotic, K-41 against drug resistant strains of Plasmodia. J. Antibiotics 55: 832 834, 2002

3) Mori, Y.; M. Tsuboi, M. Suzuki, K. Fukushima \& T. ARAI: Isolation of leucinostatin $A$ and one of its constituents, the new amino acid, 4-methyl-6-(2oxobutyl)-2-piperidinecarboxylic acid, from Paecilomyces lilacinus A-267. J. Antibiotics 35: 543 544, 1982

4) Momose, I.; W. Chen, H. Nakamura, H. Naganawa, H. IINUMA \& T. TAKEUCHI: Polyketomycin, a new antibiotic from Streptomyces sp. MK277-AF1. II. Structure determination. J. Antibiotics 51: 26 32, 1998

5) Ōmura, S.; H. Mamada, N-J. Wang, N. Imamura, R. ŌIWA, Y. IWAI \& N. Mutō: Takaokamycin, a new peptide antibiotic produced by Streptomyces sp. J. Antibiotics 37: 700 705, 1984

6) Rössner, E.; A. ZEeCK \& W. A. KöNIG: Elucidation of the structure of hormaomycin. Angew. Chem. Int. Ed. Engl. 29: 64 65, 1990
7) Andres, N.; H. Wolf, H. Zähner, E. Rössner, A. ZeECK, W. A. KÖNIG \& V. SinNwell: Stoffwechselprodukte von Mikroorganismen. Hormaomycin, ein neues Peptid-lacton mit morphogener Aktivität auf Streptomyceten. Helv. Chim. Acta 72: 426 437, 1989

8) McColm, A. A \& N. MCHARdY: Evaluation of a range of antimicrobial agents against the parasitic protozoa, Plasmodium falciparum, Babesia rodhaini and Theileria parva in vitro. Ann. Trop. Med. Parasitol. 78: 345 354, 1984

9) Gumila, C.; M. L. Ancelin, G. Jeminet, A. M. Delort, G. MiQuel \& H. J. Vial: Differential in vitro activities of ionophore compounds against Plasmodium falciparum and mammalian. Antimicrob. Agents Chemother. 40: 602 608, 1996

10) Shima, A.; K. Fukushima, T. Arai \& H. Terada: Dual inhibitory effects of the peptide antibiotics leucinostatins on oxidative phosphorylation in mitochondria. Cell Struct. Funct. 15: 53 58, 1990

11) Lucero, H. A.; R. A. Ravizzine \& R. H. Vallejos: Inhibition of spinach chloroplasts photophosphorylation by the antibiotics leucinostatin and efrapeptin. FEBS Lett. 68: 141 144, 1976

12) Csermely, P.; L. Radics, C. Rossi, M. Szamel, M. Riccl, K. Mihaly \& J. Somogyi: The nonapeptide leucinostatin $\mathrm{A}$ acts as a weak ionophore and as an immunosuppressant on $\mathrm{T}$ lymphocytes. Biochim. Biophys. Acta 31: 125 132, 1994

13) Xuan, L.; S. Xu, H. Zhang, Y. Xu \& M. Chen: Dutomycin, a new anthracycline antibiotic from Streptomyces. J. Antibiotics 45: 1974 1976, 1992

14) Nagao, K.; K. Suzuki, Tokunaga, J. Miyazaki, H. Katayama, R. Mitsuyama \& M. Uyeda: DMI-2 and DMI-3, DNA methyltransferase inhibitors produced by Streptomyces sp. strain no. 560. J. Enzyme. Inhib. 10: $115 \sim 124,1996$ 